\title{
Clinicopathologic analysis of programmed cell death-1 and programmed cell death-ligand 1 and 2 expressions in pulmonary adenocarcinoma: comparison with histology and driver oncogenic alteration status
}

Jaemoon $\mathrm{Koh}^{1}$, Heounjeong $\mathrm{Go}^{2}$, Bhumsuk Keam ${ }^{3}$, Moon-Young Kim ${ }^{1}$, Soo Jeong Nam ${ }^{1}$, Tae Min Kim ${ }^{3}$, Se-Hoon Lee ${ }^{3}$, Hye Sook Min ${ }^{4}$, Young Tae Kim ${ }^{5}$, Dong-Wan Kim ${ }^{3}$, Yoon Kyung Jeon ${ }^{1}$ and Doo Hyun Chung ${ }^{1,6,7}$

${ }^{1}$ Department of Pathology, Seoul National University Hospital, Seoul National University College of Medicine, Seoul, Republic of Korea; ${ }^{2}$ Department of Pathology, Asan Medical Center, University of Ulsan College of Medicine, Seoul, Republic of Korea; ${ }^{3}$ Department of Internal Medicine, Seoul National University Hospital, Seoul National University College of Medicine, Seoul, Republic of Korea; ${ }^{4}$ Department of Genetic Epidemiology and Preventive Medicine, Graduate School of Public Health, Seoul National University, Seoul, Republic of Korea; ${ }^{5}$ Department of Thoracic Surgery, Seoul National University Hospital, Seoul National University College of Medicine, Seoul, Republic of Korea; ${ }^{6}$ Department of Biomedical Sciences, Seoul National University College of Medicine, Seoul, Republic of Korea and ${ }^{7}$ Ischemic/Hypoxia Institute, Seoul National University College of Medicine, Seoul, Republic of Korea

Immunotherapies targeting the programmed cell death-1/programmed cell death-ligand 1 pathway have emerged as promising therapeutic strategies for lung cancer. However, the expression pattern and prognostic implications of programmed cell death-ligand 1 and 2 and programmed cell death-1 in comparison with the histology and genetic alterations in pulmonary adenocarcinomas remains unclear and thus were addressed here. Programmed cell death-ligand 1 and 2 expression in tumor cells and the quantities of programmed cell death- $1^{+}$and $\mathrm{CD}^{+}$tumor-infiltrating lymphocytes were immunohistochemically evaluated in 497 resected pulmonary adenocarcinomas and analyzed according to clinicopathological and genetic statuses. Programmed cell death-ligand 1 and 2 expression were observed in $59 \%$ and $64 \%$ of pulmonary adenocarcinomas, respectively, and showed a strong positive correlation with each other $(P<0.001)$. Programmed cell death-ligand 1 expression was higher in nodal metastasis cases $(P=0.006)$, smokers $(P=0.056)$, poorly differentiated tumors and histologic subtypes of solid and micropapillary patterns $(P<0.001)$. There was no significant difference in programmed cell death-ligand 1 and 2 expression according to EGFR mutation status. However, programmed cell death-ligand 1 expression was correlated with $A L K$ translocation $(P=0.054)$ and expression of EGFR and MET $(P<0.001)$. Meanwhile, programmed cell death-ligand 2 expression was correlated with $A L K$ translocation $(P=0.052)$, and expression of MET $(P<0.001)$ and ERBB2 $(P=0.013)$. The numbers of $\mathrm{CD}^{+}$and programmed cell death-1 $1^{+}$lymphocytes were higher in smokers $(P=0.012$ and 0.016$)$ and MET-expressing adenocarcinomas $(P<0.001)$. Patients expressing programmed cell death-ligand 1 and/or high ratios of programmed cell death $-1^{+} / \mathrm{CD}^{+}{ }^{+}$lymphocytes showed shorter disease-free survival $(P=0.001)$. Our study demonstrated that programmed cell death-ligand 1 and 2 expression varied with histology, EGFR, ALK, MET, and ERBB2 statuses, and activation of the programmed cell death-1/programmed cell death-ligand 1 pathway may be a poor prognostic factor in pulmonary adenocarcinomas.

Modern Pathology (2015) 28, 1154-1166; doi:10.1038/modpathol.2015.63; published online 17 July 2015

Correspondence: Dr YK Jeon, MD, PhD, Department of Pathology, Seoul National University Hospital, 101 Daehak-ro, Jongno-gu, Seoul 110-799, Republic of Korea or Dr DH Chung, MD, PhD, Department of Pathology and Biomedical Sciences, Seoul National University College of Medicine, 103 Daehak-ro, Jongno-gu, Seoul 110-799, Republic of Korea.

E-mail: junarplus@chol.com or doohyun@snu.ac.kr

Received 16 November 2014; revised 7 April 2015; accepted 9 April 2015; published online 17 July 2015 
Non-small-cell lung cancer is the most common cause of cancer-related death worldwide. ${ }^{1}$ The management of patients with pulmonary adenocarcinomas has shifted toward personalized therapy based on the genetic status of tumor cells. ${ }^{2-4}$ However, there are some clinical limitations. For example, resistance to molecular targeted therapies develops in most patients eventually. ${ }^{5}$ In addition, alternative treatment modalities, other than cytotoxic chemotherapy, are needed for pulmonary adenocarcinoma patients without druggable molecular alterations. To solve these issues, other strategies for pulmonary adenocarcinoma need to be established, and recently cancer immunotherapy has emerged as a promising therapeutic strategy.

Cancers evade host immune surveillance in diverse ways. A representative mechanism is utilization of the immune checkpoint pathway ${ }^{6}$ that generally refers to a variety of inhibitory interactions between $\mathrm{T}$ cells and antigen-presenting cells or host cells. Physiologically, this pathway contributes to the maintenance of self-tolerance and control of immune responses, thereby preventing autoimmunity and harmful tissue damage. ${ }^{6,7}$ However, tumor cells also harness immune checkpoints to evade the immune system, including the CD80 or CD86/ CTLA4 pathway and the programmed cell deathligand 1 or 2 /programmed cell death-1 that suppresses antitumor immune responses. ${ }^{6,8}$ Blockade of these immune checkpoints has been shown to enhance antitumor immune surveillance in vivo ${ }^{9}$ that led to the development of therapeutic reagents targeting several immune checkpoints. Among them, antagonizing anti-CTLA4 monoclonal antibodies were developed and approved for the treatment of advanced malignant melanoma patients by the US Food and Drug Administration. ${ }^{10}$ Alternatively, the programmed cell death-1/programmed cell death-ligand pathway has been suggested as a feasible immune checkpoint to inhibit tumor growth in vivo, ${ }^{11}$ as programmed cell death-1 (PD-1; encoded by $P D C D 1$ gene) attenuates immune responses by inhibiting effector T-cell proliferation and functions. ${ }^{6-8}$

The PDCD1 ligands, programmed cell death-ligand 1 (PD-L1; also called B7-H1 and encoded by CD274 gene) or programmed cell death-ligand 2 (PD-L2; also called B7-DC and encoded by PDCD1LG2 gene), have distinct expression patterns in various tissues. PD-L1 is broadly expressed in immune and nonimmune cells, whereas PD-L2 expression is limited to activated macrophages, suggesting that PD-L1 plays an important role in peripheral immune tolerance. ${ }^{6-8,12}$ During chronic viral infection, interaction between PD-1 and PD-L1 or PD-L2 leads to T-cell exhaustion that is reversed by blockade of PD-1 or programmed cell death-1 ligands (PD-Ls). ${ }^{6,8,13}$ Furthermore, $\mathrm{PD}-1^{+} \mathrm{T}$ cells were observed in tumor tissues and were functionally impaired upon engagement by PD-L1 or PD-L2. ${ }^{14-16}$ As with CTLA-4, blockade of the PD-1/PD-L pathway enhanced antitumor immune responses by restoring T-cell functions. ${ }^{11}$
Consistently, blockade of PD-1 or PD-L1 controlled the progression of various cancers and prolonged the survival of advanced pulmonary adenocarcinoma patients in clinical trials. ${ }^{17-19}$ Thus, immunotherapy targeting the PD-1/PD-L1 pathway has emerged as a highly promising therapeutic strategy for pulmonary adenocarcinoma. ${ }^{13,17-19}$

Recent studies reported that PD-1/PD-L expressions were associated with the clinicopathological features and genetic alterations of pulmonary adenocarcinoma. However, these results were conflicting. ${ }^{20-22}$ Thus, we addressed this issue in this study using a large cohort. Our study demonstrated that PD-L1 and PD-L2 expression varied with the histology and genetic alteration status and that PD-L1 expression and a high ratio of $\mathrm{PD}-1^{+} / \mathrm{CD}^{+}$ tumor-infiltrating lymphocytes were prognostic factors associated with poor outcomes in patients with pulmonary adenocarcinoma.

\section{Materials and methods}

\section{Patients and Samples}

We collected tissues from 497 patients with pulmonary adenocarcinoma who underwent surgery and had been followed up at Seoul National University Hospital (Seoul, Republic of Korea) from 2001 to 2011. None had received chemotherapy before surgery or had distant metastasis at the time of diagnosis. Clinicopathologic data and pathologic tumor-nodemetastasis (TNM) staging from the 7th American Joint Committee on Cancer were obtained from medical and pathologic records. Tumors were histologically classified according to the 2011 International Association for the Study of Lung Cancer/the American Thoracic Society/European Respiratory Society (IASLC/ATS/ERS) classification system that includes lepidic, acinar, papillary, micropapillary, and solid predominant pattern. ${ }^{23}$ In this study, adenocarcinoma in situ and minimally invasive adenocarcinoma were classified as adenocarcinoma with lepidic predominant pattern. The histologic grades were also performed based on the predominant patterns in the tumor: well differentiated (lepidic predominant), moderately differentiated (acinar or papillary predominant), and poorly differentiated (solid and micropapillary predominant). A tissue microarray was constructed from 2-mm diameter cores derived from representative tumor areas of formalin-fixed, paraffinembedded tissue blocks. This study followed the World Medical Association Declaration of Helsinki recommendations and was approved by the Institutional Review Board of Seoul National University Hospital (H-1404-100-572).

\section{Immunohistochemistry}

The specificity and sensitivity of anti-PD-L1 antibodies used for immunohistochemistry have been 
controversial. ${ }^{24-26}$ Thus, to determine the appropriate antibody to evaluate PD-L1 expression, we tested staining patterns of several commercially available antibodies against PD-L1 in human placenta and Epstein-Barr virus-positive nasopharyngeal carcinoma. A rabbit anti-PD-L1 (E1L3N) XP monoclonal antibody (Cell Signaling Technology, Danvers, MA, USA) showed the appropriate specificity and sensitivity with a clear membranous and/or cytoplasmic staining pattern and used in this study (Supplementary Figure S1). Mouse anti-PD-L2 monoclonal antibody (clone 176611, R\&D Systems, Minneapolis, MN, USA), mouse anti-PD-1 monoclonal antibody (clone MRQ-22, Cell Marque, Rocklin, CA, USA), rabbit monoclonal antibody against C-MET (SP44) (catalog no. 7904430), EGFR (clone 3C6, no. 7902988), and ERBB2 (clone 4B5) (Ventana Medical Systems, Tucson, AZ, USA) were also used. Immunohistochemistry was performed using the Benchmark XT autostainer (Ventana Medical Systems). The Bond-Max automated immunostainer (Leica Microsystems, Melbourne, Australia) was used for immunohistochemistry of CD8 (rabbit IgG, clone SP16, Thermo Scientific Fischer, Rockford, IL, USA).

The PD-L1 and PD-L2 immunohistochemistry were evaluated based on the intensity and proportion of membranous and/or cytoplasmic staining in tumor cells and scored as follows: 0, negative; 1 , weak or moderate in $<10 \%$ of tumor cells; 2 , moderate in $\geq 10 \%$ of tumor cells; 3 , strong (more intense than alveolar macrophages for PD-L1 and than tonsils for PD-L2) in $\geq 10 \%$ of tumor cells. Cases with scores of 2 or 3 were deemed positive for PD-L1 or PD-L2 expression. Alternatively, the membranous staining of PD-L1 and PD-L2 was evaluated. Cases showing complete or incomplete membranous staining in $\geq 5 \%$ of tumor cells with moderate (score 2 ) to strong (score 3) intensity were considered to be positive for PD-L1 or PD-L2 membranous expression.

Immunohistochemistry for EGFR and MET was assessed by modified criteria of previous report. ${ }^{27}$ Cases were scored into 0 (absent or only focal weak), 1 (weak to moderate in $\leq 40 \%$ of tumor cells), 2 (weak to moderate in $\geq 40 \%$ of tumor cells), and 3 (strong in $\geq 10 \%$ of tumor cells); and then classified into negative (score 0 or 1 ) and positive (score 2 or 3 ) for EGFR and MET expression. ERBB2 expression was scored from 0 to $3+$ according to the FDAapproved guidelines for the HercepTest and cases with scores of $2+$ or $3+$ were considered positive for expression.

\section{Automated Enumeration of $\mathrm{CD8}^{+}$and PD-1 ${ }^{+}$ Tumor-Infiltrating Lymphocytes}

Virtual microscope scanning of tissue microarray slides was performed for CD8 and PD-1 using Aperio ScanScope (Aperio Technologies, Vista, CA, USA), and automated enumeration of $\mathrm{CD}^{+}$and $\mathrm{PD}-1^{+}$ cells was performed by applying modified Nuclear immunohistochemistry algorithms from Aperio ImageScope software. Intact tumor areas including tumor cell nests and intervening stromal tissue were evaluated in an individual tissue core excluding areas with crush artifact or necrosis. To validate automated enumeration, we compared these values with those obtained from manual count in selected cases. Thus, the numbers of $\mathrm{PD}-1^{+}$and $\mathrm{CD}^{+}$ tumor-infiltrating lymphocytes per unit area $\left(\mathrm{mm}^{2}\right)$ were calculated and submitted for statistical analyses.

\section{Fluorescence In Situ Hybridization (FISH) Analysis for $A L K, E G F R$, and $M E T$}

Tissue microarray or whole formalin-fixed, paraffinembedded tissue blocks were submitted for FISH. To detect $A L K$ translocation, FISH analysis was performed using the LSI ALK Dual Color, Break Apart Rearrangement Probe (2p23) (Abbott Molecular, Des Plaines, IL, USA) as described previously. ${ }^{28}$ In brief, cases with separate green and red signals and/or isolated red signals in $\geq 15 \%$ of tumor cells were considered to harbor an $A L K$ translocation. EGFR gene copy number was estimated using an LSI EGFR SpectrumOrange/CEP7 SpectrumGreen probe set (Abbott Molecular) and interpreted according to the University of Colorado Cancer Center system as described previously. ${ }^{29}$ Briefly, cases with high polysomy ( $\geq 4$ copies of the EGFR gene in $\geq 40 \%$ of tumor cells) or gene amplification were deemed to be EGFR FISH positive. MET gene copy number was estimated using an LSI MET SpectrumRed/CEP7 SpectrumGreen probe (Abbott Molecular) and interpreted using the above University of Colorado Cancer Center system or Cappuzzo criteria (high $M E T$ gene copy number; mean $\geq 5$ copies per cell) as described previously. ${ }^{30}$

\section{EGFR and KRAS Mutation Analysis}

Representative hematoxylin and eosin (H\&E)-stained slides were reviewed and tumor regions were manually microdissected from consecutive formalin-fixed, paraffin-embedded tissue sections. After deparaffinization, genomic DNA was extracted and subjected to nested-PCR amplification of EGFR exons 18-21 and KRAS exon 2. PCR products were purified and subjected to direct Sanger sequencing using an ABI-PRISM 3100 DNA Analyzer (Applied Biosystems, Vernon Hills, IL, USA) as described previously. $^{31}$

\section{Statistical Analysis}

All statistical analyses were performed using SPSS software (version 21; SPSS, Chicago, IL, USA). In analysis of concordance between the 
immunohistochemistry patterns from two separate tissue microarray sets, significance of $\kappa$-value was considered as follows: value $\leq 0.40$, poor to fair concordance; 0.41-0.60, moderate concordance; 0.61-0.80, substantial concordance; 0.81-1.00, almost perfect concordance. ${ }^{32}$ Comparisons between variables were performed using the $\chi^{2}$ test, Fisher's exact test, or Student's $t$-test. Multivariate logistic regression analysis was used to examine predictive factors with consideration of collinearity. Cutoff values of $\mathrm{PD}-1^{+}$and $\mathrm{CD} 8^{+}$tumor-infiltrating lymphocyte numbers and of $\mathrm{PD}-1^{+} / \mathrm{CD}^{+}$cell ratios were determined based on the receiver operating characteristic curve at the highest positive likelihood point for disease-free survival. Disease-free survival was defined as the period between the time of surgery and that of recurrent or metastatic disease. Survival analysis was performed using the KaplanMeier method with log-rank test and multivariate Cox regression analysis. Two-sided $P$-values of $<0.05$ were considered statistically significant.

\section{Results}

Analysis of PD-L1 and PD-L2 Expression and PD-1 ${ }^{+}$ or $\mathrm{CD8}^{+}$Tumor-Infiltrating Lymphocyte Numbers in Pulmonary Adenocarcinomas Using Immunohistochemistry

The expression of PD-L1 and PD-L2 was observed in $59 \%(293 / 497)$ and $64 \%$ (316/497) of pulmonary adenocarcinomas in tumor cells (Figure 1a and Table 1). PD-L1 expression was scored as 3 in $8 \%$ (40/497) and as 2 in 51\% (253/497) of cases, whereas PD-L2 expression was scored as 3 in 15\% (72/497) and as 2 in $49 \%$ (244/497). Overall, there was a significant positive correlation between PD-L1 and PD-L2 expression $(P<0.001$; Figure 1c). When considering the membranous staining only, the PD-L1 and PD-L2 expressions were 58 and $66 \%$ of cases, showing substantial $(\kappa=0.739)$ and almost perfect agreement $(\kappa=0.863)$ with the data based on membranous and/or cytoplasmic staining (Supplementary Table S1). These results indicate that the a
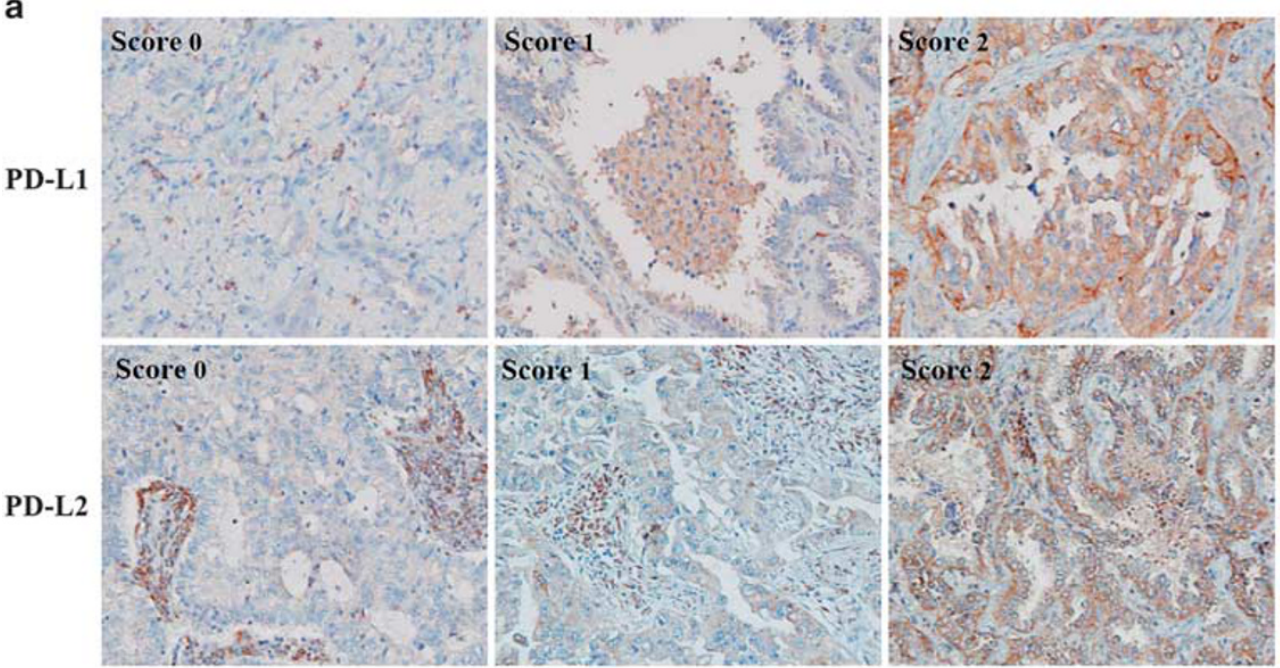
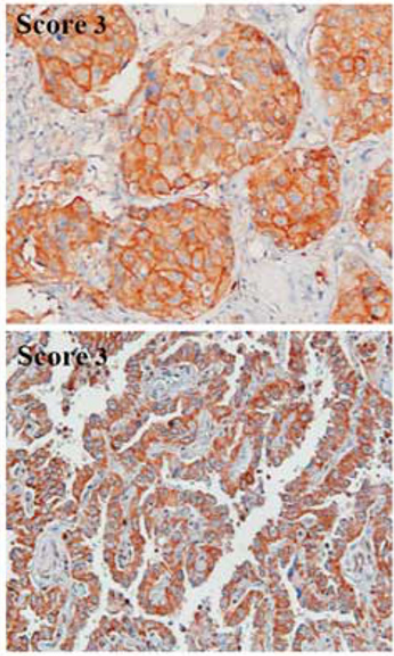

b
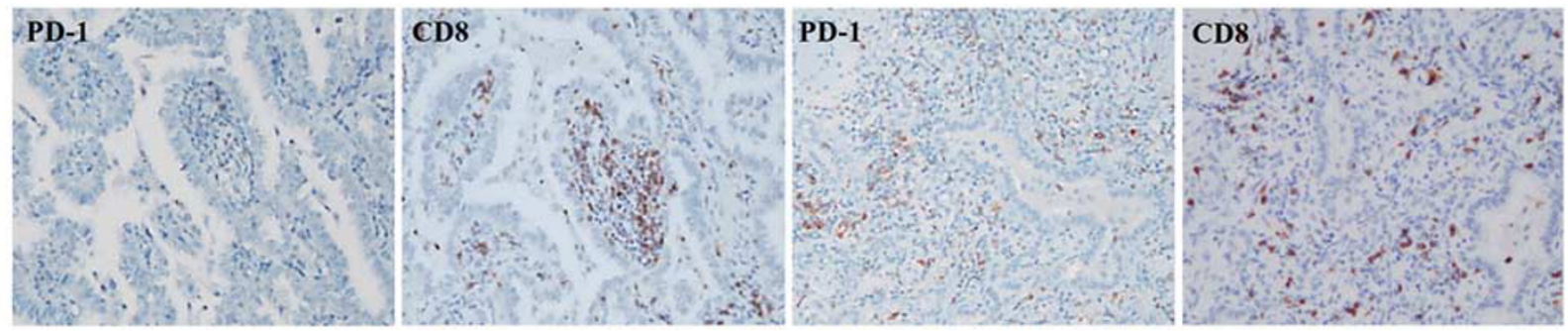

Figure 1 Representative images for PD-L1, PD-L2, PD-1, and CD8 immunohistochemistry in pulmonary adenocarcinomas and correlation between PD-L1 expression and various parameters. (a) PD-L1 was expressed in the cytoplasm and/or membrane in tumor cells, alveolar macrophages, and a few scattered immune cells. PD-L2 was predominantly immunostained in the cytoplasm of tumor cells. PD-L1 and PDL2 immunostaining was graded as absent (score 0), weak (score 1), moderate (score 2), or strong (score 3 ). A score of 2 or 3 in $>10 \%$ of tumor cells was deemed positive for PD-L1 and PD-L2 expression. (b) PD-1 and CD8 were primarily immunostained in tumor-infiltrating lymphocytes. The two images on the left show a patient with a relatively low $\mathrm{PD}-1^{+} / \mathrm{CD} 8^{+}$tumor-infiltrating lymphocyte ratio, whereas the two images on the right show another patient with a high $\mathrm{PD}-1^{+} / \mathrm{CD}^{+}$tumor-infiltrating lymphocyte ratio. (c) A strong positive correlation between PD-L1 and PD-L2 expression was observed. (d) Patients with strong PD-L1 expression (score 3) more frequently harbored wildtype EGFR than mutant EGFR, compared with those with lower PD-L1 expression. (e) Pulmonary adenocarcinomas with $A L K$ translocation exhibited higher expression of PD-L1. (f) PD-L1 expression was significantly increased relative to the levels of MET expression. 


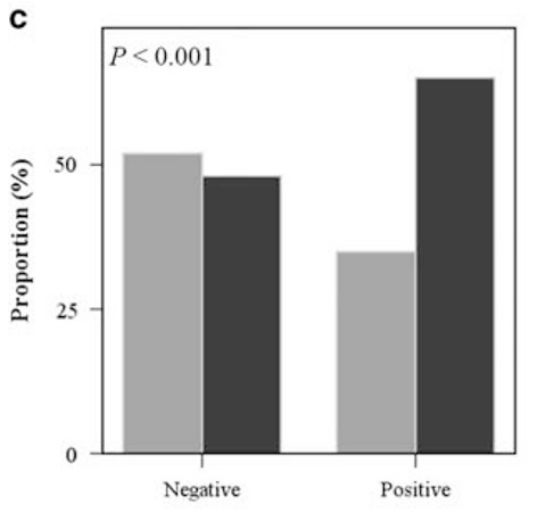

PD-L2 expression

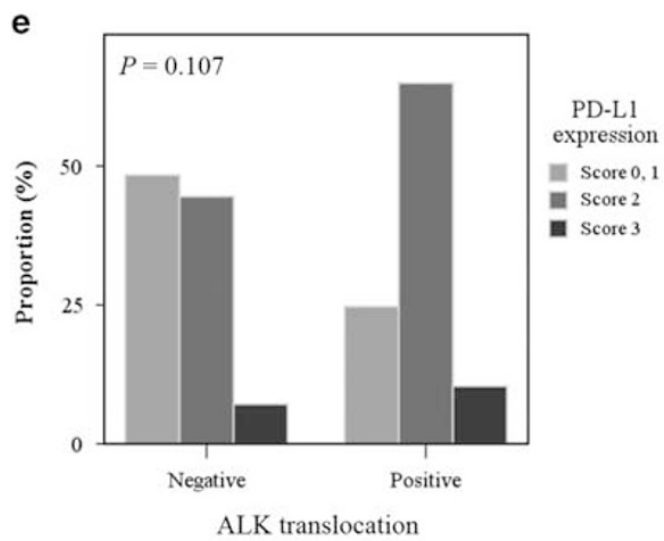

Figure 1 Continued.

concordance of two different interpretations of staining pattern, membranous/cytoplasmic staining $v s$ only the membranous staining, was high in the PD-L1 and PD-L2 immunohistochemistry. However, the frequencies of cases with score 3 of membranous staining only were lower (4\% for PD-L1 and 11\% for PD-L2) than those of membranous/cytoplasmic staining. Meanwhile, it seems that immunohistochemistry analysis for PD-Ls in pulmonary adenocarcinomas has some limitation because of core-to-core variability of tissue microarray. To address this, we compared PD-L1 and PD-L2 immunohistochemistry patterns in two separate tissue microarrays using different cores from individual tumors. Our comparative analysis revealed that $\kappa$-values for PD-L1 and PD-L2 immunohistochemistry in two tissue microarrays were 0.693 and 0.669 , respectively, indicating that concordance of immunohistochemistry patterns in two separate sets of tissue microarray was substantial in terms of expression patterns of PD-Ls in pulmonary adenocarcinomas.

The numbers of $\mathrm{PD}-1^{+}$and $\mathrm{CD}^{+}$tumor-infiltrating lymphocytes per unit area $\left(\mathrm{mm}^{2}\right)$ ranged from 0 to 284 (mean 26.47) and 0 to 851 (mean 136.39), respectively, and were correlated positively with each other $(r=0.383, \quad P<0.001$; Supplementary

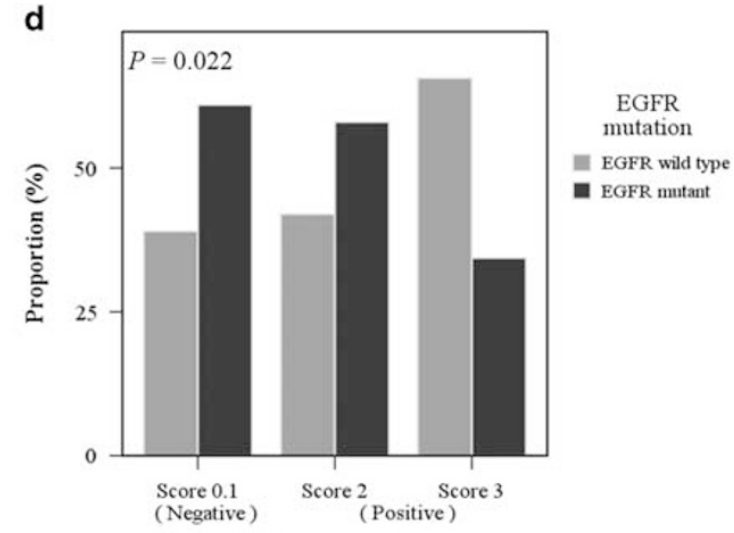

PD-L1 expression

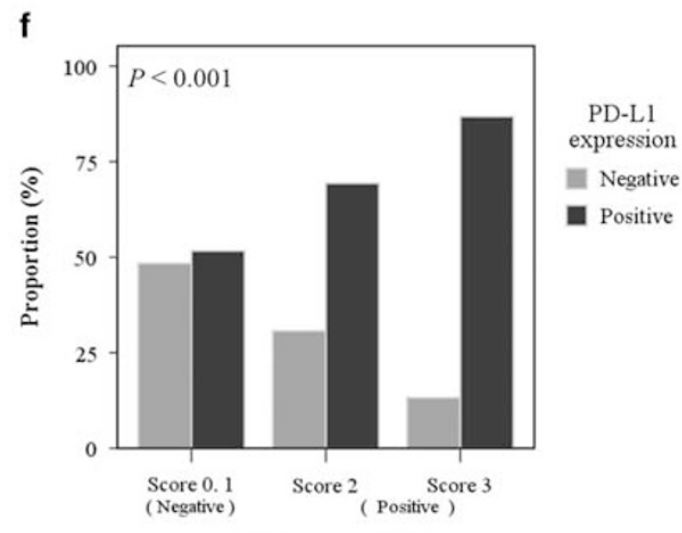

MET expression

Figure S2). Furthermore, the ratio of $\mathrm{PD}-1^{+} / \mathrm{CD}^{+}$ tumor-infiltrating lymphocytes was slightly higher in adenocarcinomas with PD-L1 expression than in those without PD-L1 expression $(P=0.066$; Figure 2a), whereas the numbers of $\mathrm{PD}^{-} 1^{+}$and $\mathrm{CD}^{+}$tumor-infiltrating lymphocytes were not different according to the PD-L1 or PD-L2 expression (Figure 2a and Supplementary Table S1). These results suggest that $\mathrm{PD}$-1-expressing $\mathrm{CD}^{+}$tumorinfiltrating lymphocytes might be relatively higher in PD-L1-positive pulmonary adenocarcinomas.

\section{Comparative Analysis of PD-L1 and PD-L2 Expression with Clinicopathological Features and Genetic Alteration Status in Pulmonary Adenocarcinomas}

The correlations between the expressions of PD-L1 and PD-L2 and the clinicopathologic features and genetic alteration status of pulmonary adenocarcinomas are summarized in Table 1 and Supplementary Table S2, and these were similar according to membranous vs membranous/cytoplasmic immunohistochemistry patterns of PD-Ls. In brief, PD-L1 was more frequently expressed in pulmonary adenocarcinomas from smokers vs never-smokers $(64 \%$ 
Table 1 Correlation between clinicopathological features and expression of PD-L1 and PD-L2 in pulmonary adenocarcinomas

\begin{tabular}{|c|c|c|c|c|c|c|}
\hline \multirow[b]{2}{*}{ Clinicopathological parameter } & \multicolumn{3}{|c|}{ PD-L1 expression } & \multicolumn{3}{|c|}{ PD-L2 expression } \\
\hline & Negative, n (\%) & Positive, n (\%) & $\mathrm{P}$ & Negative, n (\%) & Positive, n (\%) & $\mathrm{P}$ \\
\hline \multicolumn{7}{|l|}{ Gender } \\
\hline Male & $86(37)$ & $145(63)$ & 0.107 & $80(35)$ & $151(65)$ & 0.441 \\
\hline Female & $118(44)$ & $148(56)$ & & $101(38)$ & $165(62)$ & \\
\hline \multicolumn{7}{|l|}{ Age (years) } \\
\hline$<60$ & $81(39)$ & $127(61)$ & 0.419 & $68(33)$ & $140(67)$ & 0.143 \\
\hline$\geq 60$ & $123(43)$ & $166(57)$ & & $113(39)$ & $176(61)$ & \\
\hline \multicolumn{7}{|l|}{ Smoking } \\
\hline Never-smoker & $133(45)$ & $166(55)$ & 0.056 & $103(34)$ & $196(66)$ & 0.262 \\
\hline Smoker & $71(36)$ & $127(64)$ & & $78(39)$ & $120(61)$ & \\
\hline \multicolumn{7}{|l|}{ Tumor size } \\
\hline$\leq 3 \mathrm{~cm}$ & $122(41)$ & $174(59)$ & 0.926 & $100(34)$ & $196(66)$ & 0.139 \\
\hline$>3 \mathrm{~cm}$ & $82(41)$ & $119(59)$ & & $81(40)$ & $120(60)$ & \\
\hline \multicolumn{7}{|l|}{ LN metastasis } \\
\hline Absent & $164(45)$ & $203(55)$ & 0.006 & $138(38)$ & $229(62)$ & 0.357 \\
\hline Present & $40(31)$ & $90(69)$ & & $43(33)$ & $87(67)$ & \\
\hline \multicolumn{7}{|l|}{ Stage } \\
\hline I & $149(44)$ & $193(56)$ & 0.230 & $131(38)$ & $211(62)$ & 0.252 \\
\hline II & $17(37)$ & $29(63)$ & & $12(26)$ & $34(74)$ & \\
\hline III & $38(35)$ & $71(65)$ & & $38(35)$ & $71(65)$ & \\
\hline \multicolumn{7}{|l|}{ Histology (predominant pattern) } \\
\hline Lepidic & $41(61)$ & $26(39)$ & $<0.001$ & $21(31)$ & $47(69)$ & 0.251 \\
\hline Acinar & $91(42)$ & $127(58)$ & & 77 (35) & $144(65)$ & \\
\hline Papillary & $45(42)$ & $63(58)$ & & $46(42)$ & $63(58)$ & \\
\hline Solid & $20(26)$ & $56(74)$ & & $32(42)$ & $45(58)$ & \\
\hline Micropapillary & $4(18)$ & $18(82)$ & & $5(23)$ & $17(77)$ & \\
\hline \multicolumn{7}{|l|}{ Grade } \\
\hline W/D & $41(61)$ & $26(39)$ & $<0.001$ & $21(31)$ & $47(69)$ & 0.594 \\
\hline $\mathrm{M} / \mathrm{D}$ & $136(42)$ & $190(58)$ & & $123(37)$ & 207 (63) & \\
\hline $\mathrm{P} / \mathrm{D}$ & $24(25)$ & $74(75)$ & & $37(37)$ & $62(63)$ & \\
\hline \multicolumn{7}{|l|}{$A L K$ translocation } \\
\hline Negative & $199(42)$ & $275(58)$ & 0.054 & $177(37)$ & 297 (63) & 0.052 \\
\hline Positive & $5(22)$ & $18(78)$ & & $4(17)$ & $19(83)$ & \\
\hline \multicolumn{7}{|l|}{ EGFR mutation } \\
\hline Wild type & $65(38)$ & $106(62)$ & 0.240 & 66 (39) & $105(61)$ & 0.929 \\
\hline Mutant & $100(44)$ & $128(56)$ & & $87(38)$ & $141(62)$ & \\
\hline \multicolumn{7}{|l|}{ EGFR FISH ${ }^{\mathrm{a}}$} \\
\hline Negative & $60(46)$ & $72(54)$ & 0.377 & $46(35)$ & $86(65)$ & 0.802 \\
\hline Positive & $38(40)$ & $58(60)$ & & $35(36)$ & $61(64)$ & \\
\hline \multicolumn{7}{|l|}{ EGFR protein } \\
\hline Negative & $121(50)$ & $119(50)$ & $<0.001$ & $82(34)$ & $158(66)$ & 0.428 \\
\hline Positive & $81(32)$ & $169(68)$ & & $94(38)$ & $156(62)$ & \\
\hline \multicolumn{7}{|l|}{ KRAS mutation } \\
\hline Wild-type & $76(44)$ & $98(56)$ & 0.468 & $62(36)$ & $112(64)$ & 0.114 \\
\hline Mutant & $9(36)$ & $16(64)$ & & $13(52)$ & $12(48)$ & \\
\hline \multicolumn{7}{|l|}{ MET expression } \\
\hline Negative & $164(48)$ & $176(52)$ & $<0.001$ & $143(42)$ & $197(58)$ & $<0.001$ \\
\hline Positive & $39(25)$ & $117(75)$ & & $38(24)$ & $118(76)$ & \\
\hline MET FISH ${ }^{\mathrm{a}}$ & & & & & & \\
\hline Negative & $88(44)$ & $110(56)$ & 0.037 & $91(46)$ & $108(54)$ & 0.248 \\
\hline Positive & $41(33)$ & $84(67)$ & & 49 (39) & $76(61)$ & \\
\hline MET gene copy number per cell & & & & & & \\
\hline$<5$ Copies & $112(42)$ & $154(58)$ & 0.086 & $115(43)$ & $152(57)$ & 0.913 \\
\hline$\geq 5$ Copies & $17(30)$ & $40(70)$ & & $25(44)$ & $32(56)$ & \\
\hline ERBB2 expression & & & & & & \\
\hline Negative & $186(40)$ & $276(60)$ & 0.344 & $173(37)$ & $289(63)$ & 0.013 \\
\hline Positive & $12(50)$ & $12(50)$ & & $3(13)$ & $21(87)$ & \\
\hline
\end{tabular}

Abbreviations: LN, lymph node; M/D, moderately differentiated; P/D, poorly differentiated; W/D, well differentiated.

${ }^{a} E G F R$ and MET FISH status was classified according to the University of Colorado Cancer Center criteria.

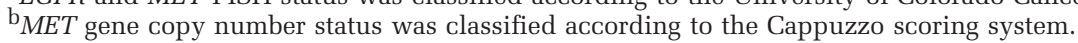


a

\section{PD-L1 expression}
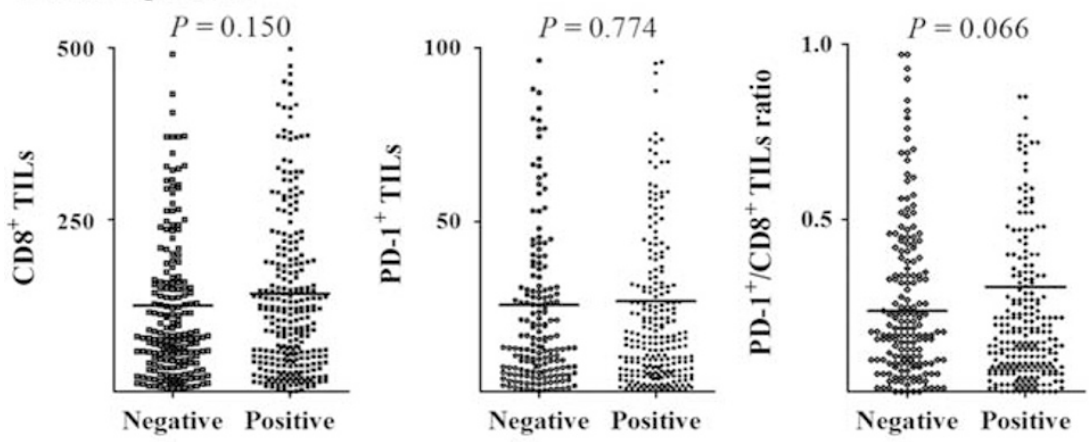

b

Smoking
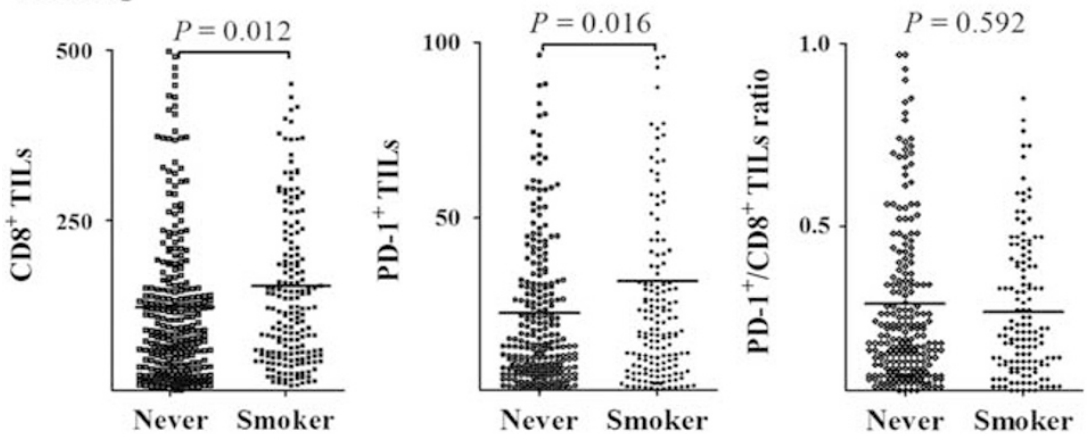

c
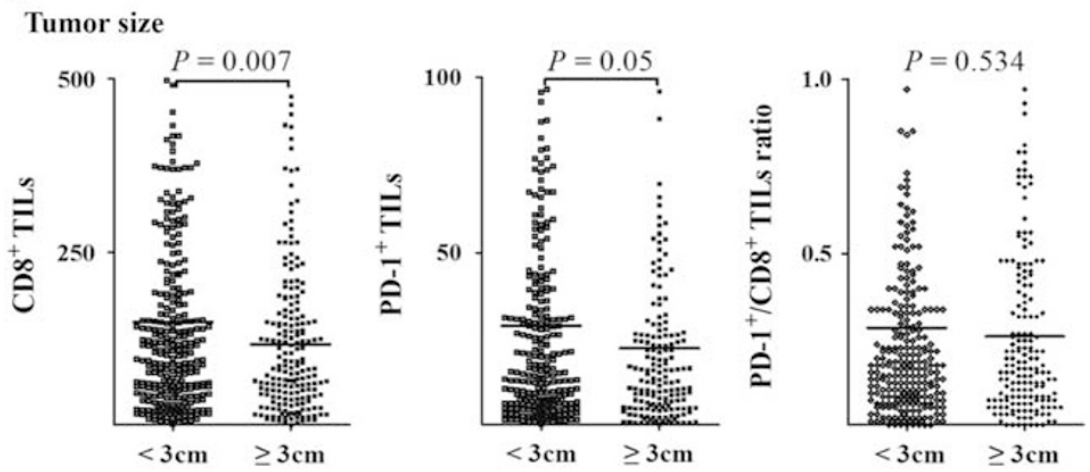

d

\section{MET expression}
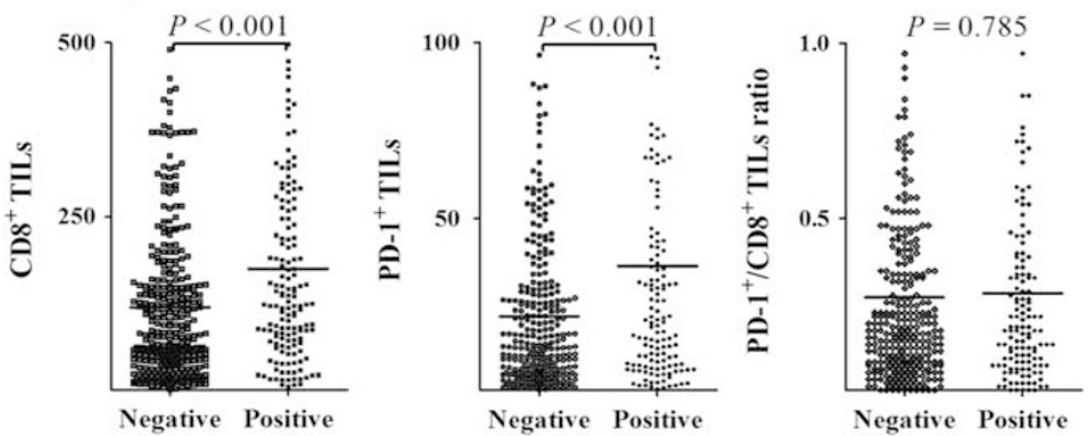

Figure 2 Dot plot diagrams comparing the numbers of PD-1 ${ }^{+}$and CD8 ${ }^{+}$tumor-infiltrating lymphocytes (TILs) and PD-1 ${ }^{+}$CD8 ${ }^{+}$TIL ratios according to (a) PD-L1 expression, (b) smoking status, (c) tumor size, and (d) MET expression. The significance of the differences in values was compared using Student's t-test. 
Table 2 Logistic regression analysis of the association of clinicopathological variables with PD-L1 and PD-L2 expression

\begin{tabular}{|c|c|c|c|}
\hline Risk factor & $\begin{array}{l}\text { Odds } \\
\text { ratio }\end{array}$ & $\begin{array}{l}95 \% \text { Confidence } \\
\text { interval }\end{array}$ & $\mathrm{P}$ \\
\hline \multicolumn{4}{|c|}{ Significant factors affecting PD-L1 expression ${ }^{\mathrm{a}}$} \\
\hline MET expression & 2.866 & $1.763-4.659$ & $<0.001$ \\
\hline $\begin{array}{l}\text { Histologic grade } \\
\text { (W/D vs M/D and P/D) }\end{array}$ & 3.881 & $2.019-7.461$ & $<0.001$ \\
\hline EGFR expression & 2.038 & $1.302-3.191$ & 0.002 \\
\hline PD-L2 expression & 1.636 & $1.031-2.598$ & 0.037 \\
\hline \multicolumn{4}{|c|}{ Significant factors affecting PD-L2 expression ${ }^{\mathrm{b}}$} \\
\hline MET expression & 2.163 & $1.350-3.467$ & 0.001 \\
\hline ERBB2 expression & 5.104 & $1.124-23.186$ & 0.035 \\
\hline PD-L1 expression & 1.593 & $1.024-2.477$ & 0.039 \\
\hline
\end{tabular}

Abbreviations: M/D, moderately differentiated; P/D, poorly differentiated; W/D, well differentiated.

${ }^{a}$ Variables included gender, age, smoking, tumor size, lymph node metastasis, histology (W/D (reference) vs $\mathrm{M} / \mathrm{D}$ and P/D), a ratio of PD- $1^{+} / \mathrm{CD}^{+}$tumor-infiltrating lymphocytes $(<0.25$ (reference) vs $\geq 0.25$ ), EGFR mutation, EGFR expression, MET expression, ALK translocation, ERBB2 expression, and PD-L2.

b Variables included gender, age, smoking, tumor size, lymph node metastasis, histology (W/D (reference) vs $\mathrm{M} / \mathrm{D}$ and $\mathrm{P} / \mathrm{D}$ ), a ratio of $\mathrm{PD}-1^{+} / \mathrm{CD}^{+}$tumor-infiltrating lymphocytes $(<0.25$ (reference) vs $\geq 0.25$ ), EGFR mutation, EGFR expression, MET expression, ALK translocation, ERBB2 expression, and PD-L1.

vs $56 \%, P=0.056)$. PD-L1 expression was significantly higher among patients with lymph node (LN) metastasis than those without nodal metastasis $(69 \%$ vs $55 \%, P=0.006)$. Of note, PD-L1 expression rates were closely related with the histologic patterns and grades of tumors; $39 \%$ in lepidic predominant welldifferentiated adenocarcinomas, $58 \%$ in acinar or papillary predominant moderately differentiated adenocarcinomas, and $76 \%$ in solid or micropapillary predominant poorly differentiated adenocarcinomas $(P<0.001)$. In contrast, PD-L2 expression was not significantly different in pulmonary adenocarcinomas according to smoking status, TNM stage, or histologic pattern and grade.

PD-L1 expression (scores 2 and 3) rate was not statistically different between adenocarcinomas harboring wild-type EGFR and those harboring an EGFR mutation (Table 1). However, a strong PD-L1 expression (score 3) was more frequently observed in adenocarcinomas with wild-type EGFR (12\%) than in those with mutated EGFR (5\%, $P=0.022$; Figure 1d). Meanwhile, $74 \%$ of adenocarcinomas with $A L K$ translocation but $58 \%$ of those without $A L K$ translocation expressed PD-L1 $(P=0.054$; Table 1). In particular, adenocarcinomas with $A L K$ translocation tended to exhibit a strong PD-L1 expression more frequently than those without $A L K$ translocation $(13 \%$ vs $8 \%, P=0.107$; Figure $1 \mathrm{e})$. Furthermore, PD-L1 expression showed a significant positive correlation with EGFR expression (68\% vs $50 \%, P<0.001)$, MET expression $(75 \%$ vs $52 \%$, $P<0.001)$, and MET FISH-positive status
(67\% vs 56\%, P=0.037; Table 1 and Figure 1f). Meanwhile, PD-L2 expression was also more common in adenocarcinomas harboring $A L K$ translocation $(P=0.052)$ and significantly higher in those showing MET $(P<0.001)$ and ERBB2 expression $(P=0.013$; Table 1$)$.

Logistic regression analysis (for variables including gender, age, smoking, tumor size, LN metastasis, histology, a ratio of $\mathrm{PD}-1^{+} / \mathrm{CD}^{+}$tumor-infiltrating lymphocytes, EGFR mutation, $A L K$ translocation, and expressions of EGFR, MET, ERBB2, and PD-L2) revealed that histology and expression of MET, EGFR, and PD-L2 were significant parameters independently affecting PD-L1 expression in pulmonary adenocarcinomas (Table 2).

\section{Comparative Analysis of PD- $1^{+}$and $\mathrm{CDB}^{+}$ \\ Tumor-Infiltrating Lymphocyte Numbers with Clinicopathological Features and Genetic Alteration Status in Pulmonary Adenocarcinomas}

Comparative analysis of the numbers of $\mathrm{PD}-1^{+}$and $\mathrm{CD}^{+}$tumor-infiltrating lymphocytes and the $\mathrm{PD}-1^{+} /$ $\mathrm{CD}^{+}$tumor-infiltrating lymphocyte ratio with clinicopathological features and genetic status is detailed in Supplementary Table S3, and the representative results are displayed in Figure 2. In brief, higher numbers of $\mathrm{CD}^{+}$cells were detected in adenocarcinomas $\leq 3 \mathrm{~cm}$ than in those $>3 \mathrm{~cm}$ $(P=0.007$; Figure 2c) and in smokers than in neversmokers $\left(P=0.012\right.$; Figure 2b). $\mathrm{PD}-1^{+}$cells were also greater in number in adenocarcinomas $\leq 3 \mathrm{~cm}$ $(P=0.05$; Figure 2c) and in smokers $(P=0.016$; Figure 2b). Of note, significantly higher numbers of $\mathrm{PD}-1^{+}$and $\mathrm{CD} 8^{+}$tumor-infiltrating lymphocytes were found in MET expression-positive adenocarcinomas compared with MET expression-negative cases $(P<0.001$ for both; Figure 2d and Supplementary Table S3). Numbers of $\mathrm{CD}^{+}$cells were high in well-differentiated tumors, intermediated in moderately differentiated tumors, and low in poorly differentiated tumors. However, there was no significant difference in the numbers of $\mathrm{PD}-1^{+}$cells according to the histologic grade.

\section{Prognostic Significance of PD-L1 and PD-L2 Expressions and $\mathrm{PD}-\mathrm{1}^{+}$and $\mathrm{CD8}^{+}$Tumor-Infiltrating Lymphocyte Numbers in Pulmonary Adenocarcinomas}

In univariate survival analysis, alleged prognostic factors including stage, tumor size, and LN metastasis were significantly associated with disease-free survival in patients with pulmonary adenocarcinoma (all $P<0.001$; data not shown). PD-L1, but not PD-L2, expression was significantly correlated with poor disease-free survival $(P=0.030$; Figure 3a). Membranous PD-L1, but not PD-L2, expression also showed a significant association with shorter diseasefree survival ( $P=0.018$; Supplementary Figure S3). A high number of $\mathrm{PD}^{-} 1^{+}$or $\mathrm{CD}^{+}$tumor-infiltrating 

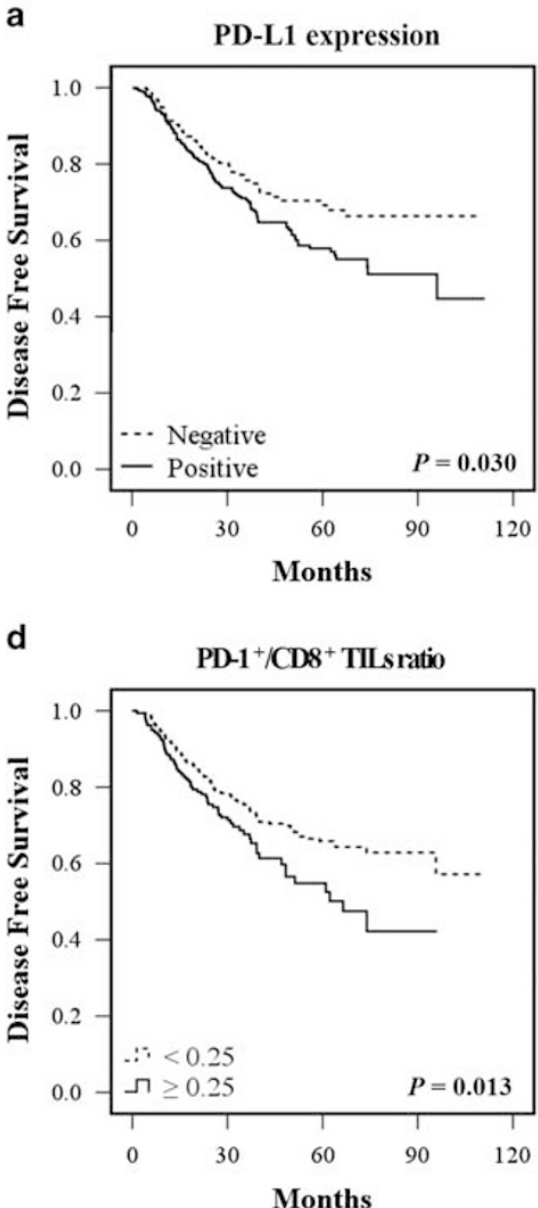

b

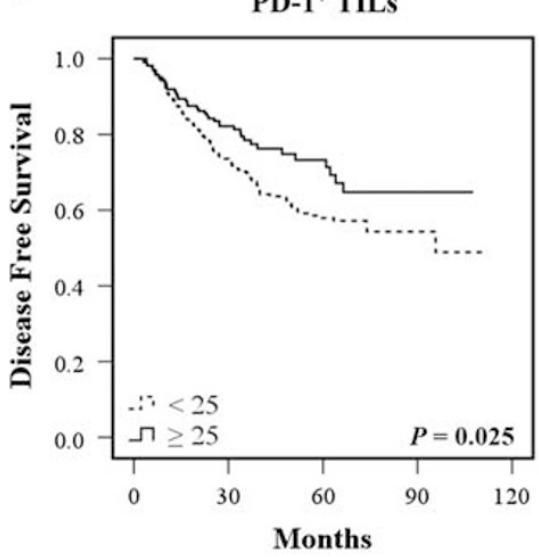

e

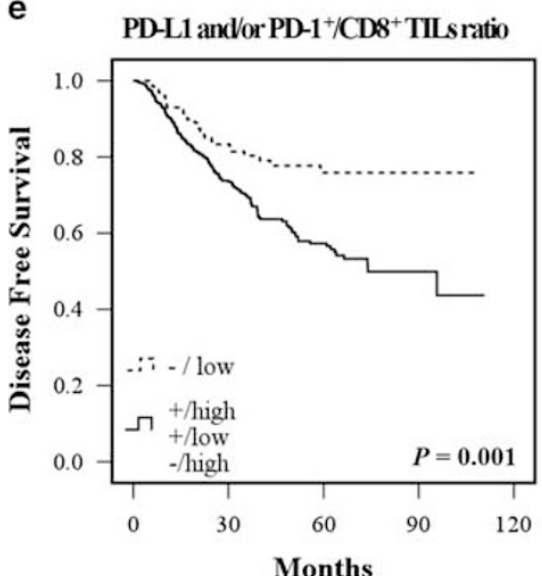

c

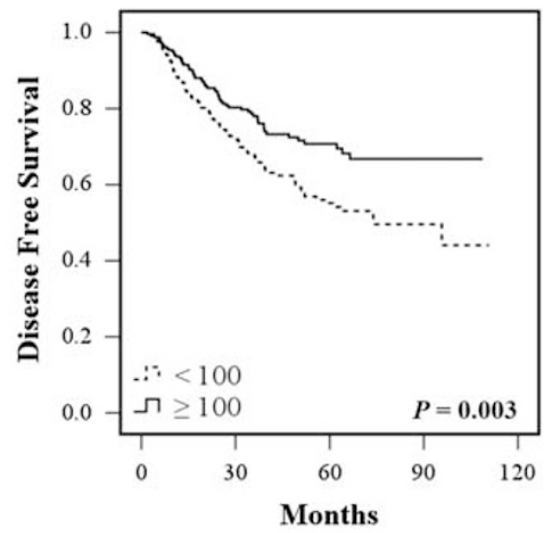

f

PD-L2 and/or PD-1 ${ }^{+} / \mathrm{CD}^{+}{ }^{+}$TILsratio

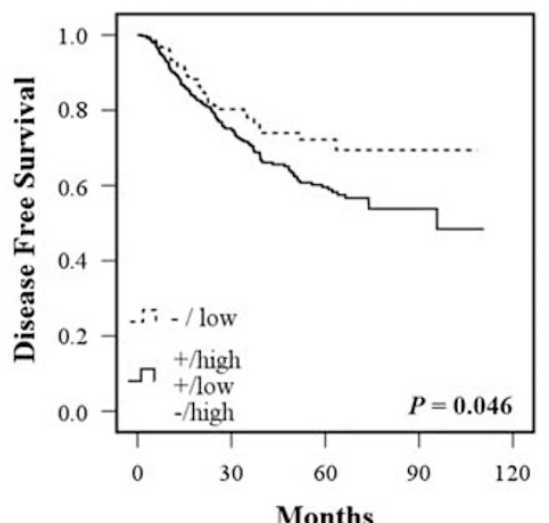

Figure 3 Kaplan-Meier plots with the log-rank test for disease-free survival in pulmonary adenocarcinoma patients. (a) Patients expressing PD-L1 showed shorter disease-free survival. (b and $\mathbf{c})$ Pulmonary adenocarcinoma patients with a high number of PD-1 ${ }^{+}$tumorinfiltrating lymphocytes (TILs) with a cutoff of $25 / \mathrm{mm}^{2}$ or CD8 $8^{+}$TILs with a cutoff of $100 / \mathrm{mm}^{2}$ exhibited prolonged disease-free survival. (d) A high ratio of PD- $1^{+} / \mathrm{CD}^{+}$TILs with a cutoff of 0.25 was significantly associated with shortened disease-free survival. (e) Patients with PD-L1 expression and/or a high PD-1 $/$ CD8 ${ }^{+}$TIL ratio displayed significantly poorer disease-free survival than those with negative PD-L1 expression and a low PD-1+/CD8 ${ }^{+}$TIL ratio. (f) The disease-free survival of pulmonary adenocarcinoma patients expressing PD-L2 and/or exhibiting high ratios of $\mathrm{PD}-1^{+} / \mathrm{CD}^{+}$TILs was also diminished.

lymphocytes was associated with significantly prolonged disease-free survival $(P=0.025$ and 0.003 , respectively; Figure $3 \mathrm{~b}$ and $\mathrm{c})$. However, a higher ratio of $\mathrm{PD}-1^{+} / \mathrm{CD}^{+}$tumor-infiltrating lymphocytes (defined as $\geq 0.25$ ) was associated with a much shorter disease-free survival $(P=0.013$; Figure 3d). Moreover, patients with PD-L1 expression and/or high $\mathrm{PD}-1^{+} / \mathrm{CD}^{+}$tumor-infiltrating lymphocyte ratio displayed significantly shorter disease-free survival compared with those lacking PD-L1 expression and showing a low $\mathrm{PD}-1^{+} / \mathrm{CD}^{+}$ tumor-infiltrating lymphocyte ratio $(P=0.001$; Figure 3e). Similarly, the combination of PD-L2 expression and/or a high $\mathrm{PD}-1^{+} / \mathrm{CD}^{+}$tumor-infiltrating lymphocyte ratio was also correlated with shorter disease-free survival ( $P=0.046$; Figure $3 f)$.

Multivariate analysis including gender, age, histologic grade, stage, combined PD-L1 expression and/or $\mathrm{PD}-1^{+} / \mathrm{CD}^{+}$tumor-infiltrating lymphocyte ratio, and PD-L2 expression as variables revealed that histologic grade (well-differentiated (reference) vs moderately to poorly differentiated; odds ratio (OR), 2.486; 95\% confidence interval (CI), 1.2045.134; $P=0.014$ ), stage (I (reference) vs II-III; OR, 2.289; 95\% CI, 1.481-3.538; $P<0.001$ ), and combined PD-L1 expression and/or PD- $1^{+} / \mathrm{CD}^{+}$tumorinfiltrating lymphocyte ratio (no PD-L1 expression and low $\mathrm{PD}-1^{+} / \mathrm{CD}^{+}$tumor-infiltrating lymphocyte ratio (reference) vs others; OR, 1.771; 95\% CI, 1.1682.687; $P=0.007$ ) were independent prognostic factors for disease-free survival.

\section{Discussion}

Our study demonstrated that PD-L1 and PD-L2 were variably expressed in pulmonary adenocarcinomas according to the histologic pattern and genetic alteration status. The expression rate of PD-L1 in pulmonary adenocarcinomas was $\sim 60 \%$, and 
this was higher compared with several previous studies, ${ }^{20,25}$ but lower compared with a very recent study. ${ }^{22}$ This might be attributable to the use of different antibodies and interpretation criteria in the lack of consensus PD-L1 immunohistochemistry method at present. In this study, PD-L1 and PD-L2 expression determined by immunohistochemistry in pulmonary adenocarcinomas were closely correlated with each other. This observation was consistent with the mRNA expression data from 129 pulmonary adenocarcinomas archived in The Cancer Genome Atlas (http://tcga-data.nci.nih.gov/tcga/) $(P<0.001)$. Moreover, pulmonary adenocarcinomas expressing PD-L1 tended to have higher $\mathrm{PD}-1^{+} / \mathrm{CD}^{+}$tumorinfiltrating lymphocyte ratio than PD-L1-negative tumors. These findings suggest that PD-L1 expression by pulmonary adenocarcinomas might be involved in immune regulation via the PD-1/PD-L1 pathway within the tumor microenvironment.

Previously, several studies demonstrated the PD-L1 expression patterns in both adenocarcinoma and squamous cell carcinoma of the lung. ${ }^{20-22,25}$ However, only a few studies performed analysis on the PD-L1 expression according to the histologic classification of pulmonary adenocarcinomas using IASLC/ATS/ERS (2011) system..$^{20,33}$ Our study showed that PD-L1, but not PD-L2, expression was significantly and independently associated with histologic grades of pulmonary adenocarcinomas. Given that poorly differentiated pulmonary adenocarcinomas usually show more aggressive behavior than well-differentiated ones and PD-L1 expression in tumor cells may exert immune evasion of cancers, it is suggested that high PD-L1 expression may be one of the candidates to explain progression and aggressive biologic behavior of pulmonary adenocarcinomas with poor differentiation.

Both intrinsic and extrinsic mechanisms contribute to induction of PD-L1 (CD274) expression in tumor cells. ${ }^{6,34}$ During antitumor immune responses in vivo, various immune and tumor cells produce cytokines that upregulate PD-L1 (CD274) extrinsically in a paracrine and/or autocrine manner. ${ }^{6,35} \mathrm{In}$ contrast, an intrinsic mechanism refers to constitutive PD-L1 expression by oncogenic signaling, such as NPM-ALK translocation, PI3K/Akt activation, or chronic viral infection, ${ }^{26,34,36}$ suggesting that intrinsic genetic alterations in tumor cells might account for regulation of the PD-1/PD-L pathway. Moreover, several driver mutations have emerged as therapeutic targets for patients with pulmonary adenocarcinoma. Thus, comparative evaluation between the PD-1/PD-L1, PD-L2 pathway, and genetic alterations in pulmonary adenocarcinomas may have clinical relevance. Our study demonstrated that PD-L1 and PD-L2 expression varied based on the $E G F R, A L K, M E T$, and ERBB2 statuses in pulmonary adenocarcinomas.

Recently, it was demonstrated that overexpression of PD-L1 could be induced in tumor cells showing resistance to targeted therapies against BRAF and
EGFR. ${ }^{15,37}$ However, it has also been reported that PD-L1 expression was not associated with EGFR, $K R A S$, or $B R A F$ mutation or $A L K$ translocation. ${ }^{20}$ In contrast, other studies reported that PD-L1 overexpression was associated with EGFR mutation in non-small-cell lung cancer. ${ }^{21,22}$ In this study, although a strong expression of PD-L1 was more common in pulmonary adenocarcinomas with wild-type EGFR, there was overall no significant difference in PD-L1 expression according to EGFR mutation status. This was comparable to previous in vitro studies demonstrating that EGFR pathway activation triggered upregulation of PD-L1 in lung cancer cells in an EGFR mutation-independent manner, and that PD-L1 (CD274) mRNA levels were not statistically different between lung cancer cell lines harboring and lacking EGFR mutation. ${ }^{15}$ Meanwhile, a strong positive correlation between EGFR with PD-L1 expression observed in this study hints that the EGFR pathway might contribute to the upregulation of PD-L1 in pulmonary adenocarcinomas. Of note, patients with $A L K$ translocation tended to show high expression of both PD-L1 and PD-L2 in pulmonary adenocarcinomas. Consistent with this, ALK activity by $N P M-A L K$ translocation induced PDL1 (CD274) expression in T- cell lymphoma. ${ }^{34}$ Thus, these results imply that $A L K$ translocation might contribute to the PD-L1 and PD-L2 expression in pulmonary adenocarcinomas, although the number of patients with $A L K$ translocation included in this study was too small for this result to reach statistical significance. In this study, PD-L1 and PD-L2 expression were significantly and independently associated with MET expression. These were correlated with The Cancer Genome Atlas lung adenocarcinoma genome data that also showed a strong tendency toward co-occurrence among CD274, PDCD1LG2, and $M E T$ mRNA expression $(P<0.001$ and $P=0.027$, respectively). Intriguingly, a greater number of PD-1 ${ }^{+}$ or $\mathrm{CD}^{+}$cells infiltrated MET-positive pulmonary adenocarcinomas. MET plays an important role in the progression and aggressiveness of pulmonary adenocarcinomas via activation of oncogenic signaling pathways. ${ }^{38}$ Thus, it is conceivable that MET may also be involved in immune evasion by regulating PD-1/PD-L pathway. Moreover, considering that MET amplification is one of the major mechanisms mediating acquired resistance to EGFR tyrosine kinase inhibitor in EGFR-mutated pulmonary adenocarcinomas, ${ }^{39}$ it is hypothesized that MET might regulate the PD-1/PD-L1 pathway in patients resistant to EGFR tyrosine kinase inhibitor, and this should be verified by further study.

The prognostic implications of PD-Ls and PD-1 in non-small-cell lung cancer have been controversial. ${ }^{25,40-42}$ PD-1 and PD-L1 blockade has shown to prolong survival in patients with advanced lung cancer, ${ }^{17,18,43}$ indicating that activation of the PD-1/ PD-L pathway inhibits tumor surveillance, thus implicating this pathway as an adverse prognostic factor. However, a recent study demonstrated that 
PD-L1 (CD274) expression at the protein and mRNA levels was associated with better clinical outcomes in patients with non-small-cell lung cancer. ${ }^{25}$ This discrepancy may be attributed to differences in PDL1 (CD274) detection methods and heterogeneous populations of various non-small-cell lung cancer subtypes, stages, and treatment modalities. ${ }^{22}$ To minimize these issues, we compared the clinical features associated with disease-free survival among a large cohort of pulmonary adenocarcinoma patients who underwent surgical resection. Our study revealed that PD-L1 expression was a poor prognostic factor in patients with pulmonary adenocarcinoma. Consistent with our results, several reports claimed that elevated PD-L1 expression was predictive of poor clinical outcomes in several cancers including non-small-cell lung cancer. ${ }^{41,42}$ Furthermore, upon interaction with PD-1, PD-L1 contributed to an anti-apoptotic effect in tumor cells in a cytosolic domain-dependent manner, ${ }^{44}$ indicating that PD-L1 expression in tumor cells might not only induce T-cell exhaustion but also inhibit tumor cell death. In our study, although increased number of $\mathrm{CD}^{+}$or $\mathrm{PD}^{-} 1^{+}$tumor-infiltrating lymphocytes were associated with prolonged disease-free survival, a high ratio of $\mathrm{PD}-1^{+} / \mathrm{CD}^{+}$tumor-infiltrating lymphocytes was associated with shorter diseasefree survival. Several groups demonstrated that increased $\mathrm{CD}^{+}$tumor-infiltrating lymphocytes and even $\mathrm{PD}-1^{+}$tumor-infiltrating lymphocytes were a favorable prognostic factor in various types of cancers. ${ }^{45-48}$ These studies suggested that increased PD $-1^{+}$tumor-infiltrating lymphocytes may reflect a subset of immune cells previously activated by the antitumor immune response, and thereby correlated with a favorable clinical outcome ${ }^{48}$ However, PD-1 ${ }^{+}$ $\mathrm{T}$ cells have been regarded as functionally exhausted rather than activated because of chronic and persistent antigenic exposure from either viral infection or the tumor microenvironment, suggesting that the $\mathrm{PD}-1^{+} / \mathrm{CD}^{+}$tumor-infiltrating lymphocyte ratio might reflect attenuated cytotoxicity of $\mathrm{CD}^{+} \mathrm{T}$ cells against tumors. This suggestion may account for the clinical implication that a high $\mathrm{PD}-1^{+} / \mathrm{CD}^{+}$tumorinfiltrating lymphocyte ratio is a poor prognostic factor for pulmonary adenocarcinomas in this study. Moreover, it has been demonstrated that the main subset of tumor-infiltrating immune cells expressing PD-1 were $\mathrm{CD}^{+}$rather than $\mathrm{CD}^{+}{ }^{+} \mathrm{T}$ cells, ${ }^{14-16,49}$ supporting that $\mathrm{PD}-1^{+}$cells in pulmonary adenocarcinomas are primarily $\mathrm{CD}^{+} \mathrm{T}$ cells. Thus, it is reasonable that high $\mathrm{PD}-1^{+} / \mathrm{CD}^{+}$tumor-infiltrating lymphocyte ratios and PD-L1 expression in tumors might inhibit specific immune responses against tumor cells that may be a useful parameter for unfavorable prognosis of patients with pulmonary adenocarcinoma.

There are several important issues regarding the therapeutic application of the PD-1/PD-L1 pathway in non-small-cell lung cancer. First, the predictive biomarkers for PD-1/PD-L1-targeting immunotherapy remain unclear. In a recent clinical trial for the anti-PD-L1 antibody, MPDL3280A, PD-1/PD-L1 blockade induced objective responses in $\sim 20 \%$ of patients with advanced non-small-cell lung cancers, ${ }^{17,18}$ associated with PD-L1 expression levels estimated using immunohistochemistry and with smoking status. ${ }^{43}$ Our study demonstrated that the expression of PD-L1 and PD-1 in pulmonary adenocarcinomas varied with genetic alteration status but not limited to a specific genetic subset. Thus, we hypothesize that evaluation of PD-L1 expression and/or high $\mathrm{PD}-1^{+} / \mathrm{CD}^{+}$tumor-infiltrating lymphocyte ratio before immunotherapy may be useful in predicting responses to immunotherapy for patients with pulmonary adenocarcinoma regardless of genetic alteration status. Second, the efficiency and usefulness of PD-1/PD-L1-targeted immunotherapy as adjuvant therapy for pulmonary adenocarcinomas has not been established. Activation of the PD-1/PDL1 pathway was associated with poor disease-free survival in pulmonary adenocarcinoma patients with postoperative status in our study, suggesting that PD-1/PD-L1-targeted therapy could be considered as an adjuvant treatment for pulmonary adenocarcinoma patients in the future.

In conclusion, PD-L1 and PD-L2 expression in pulmonary adenocarcinomas varied in terms of EGFR, ALK, MET, and ERBB2 alteration statuses, and activation of the PD-1/PD-L1, PD-L2 pathway predicted poor prognosis for pulmonary adenocarcinoma. Thus, PD-1/PD-L1, PD-L2 pathway-targeted immunotherapy may be useful for treatment of patients with pulmonary adenocarcinoma.

\section{Acknowledgments}

This study was supported by a grant from the National R\&D Program for Cancer Control, Ministry for Health and Welfare, Republic of Korea (1220220).

\section{Disclosure/conflict of interest}

The authors declare no conflict of interest.

\section{References}

1 Siegel R, Naishadham D, Jemal A. Cancer statistics, 2013. CA Cancer J Clin 2013;63:11-30.

2 Reck M, Heigener DF, Mok T et al. Management of nonsmall-cell lung cancer: recent developments. Lancet 2013;382:709-719.

3 Mok TS, Wu YL, Thongprasert S et al. Gefitinib or carboplatin-paclitaxel in pulmonary adenocarcinoma. N Engl J Med 2009;361:947-957.

4 Shaw AT, Kim DW, Nakagawa K et al. Crizotinib versus chemotherapy in advanced ALK-positive lung cancer. N Engl J Med 2013;368:2385-2394.

5 Ohashi K, Maruvka YE, Michor F et al. Epidermal growth factor receptor tyrosine kinase inhibitorresistant disease. J Clin Oncol 2013;31:1070-1080. 
6 Pardoll DM. The blockade of immune checkpoints in cancer immunotherapy. Nat Rev Cancer 2012;12: 252-264.

7 Nishimura H, Honjo T. PD-1: an inhibitory immunoreceptor involved in peripheral tolerance. Trends Immunol 2001;22:265-268.

8 Okazaki T, Honjo T. PD-1 and PD-1 ligands: from discovery to clinical application. Int Immunol 2007;19: 813-824.

9 Leach DR, Krummel MF, Allison JP. Enhancement of antitumor immunity by CTLA-4 blockade. Science 1996;271:1734-1736.

10 Ott PA, Hodi FS, C Robert. CTLA-4 and PD-1/PD-L1 blockade: new immunotherapeutic modalities with durable clinical benefit in melanoma patients. Clin Cancer Res 2013;19:5300-5309.

11 Iwai Y, Ishida M, Tanaka Y et al. Involvement of PD-L1 on tumor cells in the escape from host immune system and tumor immunotherapy by PD-L1 blockade. Proc Natl Acad Sci USA 2002;99:12293-12297.

12 Rozali EN, Hato SV, Robinson BW et al. Programmed death ligand 2 in cancer-induced immune suppression. Clin Dev Immunol 2012;2012:656340.

13 Zielinski C, Knapp S, Mascaux C et al. Rationale for targeting the immune system through checkpoint molecule blockade in the treatment of non-small-cell lung cancer. Ann Oncol 2013;24:1170-1179.

14 Ahmadzadeh M, Johnson LA, Heemskerk B et al. Tumor antigen-specific CD8 $\mathrm{T}$ cells infiltrating the tumor express high levels of PD-1 and are functionally impaired. Blood 2009;114:1537-1544.

15 Akbay EA, Koyama S, Carretero J et al. Activation of the PD-1 pathway contributes to immune escape in EGFRdriven lung tumors. Cancer Discov 2013;3:1355-1363.

16 Zhang Y, Huang S, Gong D et al. Programmed death-1 upregulation is correlated with dysfunction of tumorinfiltrating CD8+ T lymphocytes in human non-small cell lung cancer. Cell Mol Immunol 2010;7:389-395.

17 Topalian SL, Hodi FS, Brahmer JR et al. Safety, activity, and immune correlates of anti-PD-1 antibody in cancer. N Engl J Med 2012;366:2443-2454.

18 Brahmer JR, Tykodi SS, Chow LQ et al. Safety and activity of anti-PD-L1 antibody in patients with advanced cancer. N Engl J Med 2012;366:2455-2465.

19 Ribas A. Tumor immunotherapy directed at PD-1. N Engl J Med 2012;366:2517-2519.

20 Yang CY, Lin MW, Chang YL et al. Programmed cell death-ligand 1 expression in surgically resected stage I pulmonary adenocarcinoma and its correlation with driver mutations and clinical outcomes. Eur J Cancer 2014;50:1361-1369.

21 Azuma K, Ota K, Kawahara A et al. Association of PDL1 overexpression with activating EGFR mutations in surgically resected nonsmall-cell lung cancer. Ann Oncol 2014;25:1935-1940.

22 D'Incecco A, Andreozzi M, Ludovini V et al. PD-1 and PD-L1 expression in molecularly selected nonsmall-cell lung cancer patients. Br J Cancer 2014;112: 95-102.

23 Travis WD, Brambilla E, Noguchi $\mathrm{M}$ et al. International Association for the Study of Lung Cancer/American Thoracic Society/European Respiratory Society International multidisciplinary classification of lung adenocarcinoma. J Thorac Oncol 2011;6:244-285.

24 Gadiot J, Hooijkaas AI, Kaiser AD et al. Overall survival and PD-L1 expression in metastasized malignant melanoma. Cancer 2011;117:2192-2201.
25 Velcheti V, Schalper KA, Carvajal DE et al. Programmed death ligand-1 expression in non-small cell lung cancer. Lab Invest 2014;94:107-116.

26 Chen BJ, Chapuy B, Ouyang J et al. PD-L1 expression is characteristic of a subset of aggressive B-cell lymphomas and virus-associated malignancies. Clin Cancer Res 2013;19:3462-3473.

27 Tsao MS, Liu N, Chen JR et al. Differential expression of Met/hepatocyte growth factor receptor in subtypes of non-small cell lung cancers. Lung Cancer 1998;20: 1-16.

28 Park HS, Lee JK, Kim DW et al. Immunohistochemical screening for anaplastic lymphoma kinase (ALK) rearrangement in advanced non-small cell lung cancer patients. Lung Cancer 2012;77:288-292.

29 Jeon YK, Sung SW, Chung JH et al. Clinicopathologic features and prognostic implications of epidermal growth factor receptor (EGFR) gene copy number and protein expression in non-small cell lung cancer. Lung Cancer 2006;54:387-398.

30 Go H, Jeon YK, Park HJ et al. High MET gene copy number leads to shorter survival in patients with nonsmall cell lung cancer. J Thorac Oncol 2010;5:305-313.

$31 \mathrm{Kim}$ YT, Seong YW, Jung YJ et al. The presence of mutations in epidermal growth factor receptor gene is not a prognostic factor for long-term outcome after surgical resection of non-small-cell lung cancer. J Thorac Oncol 2013;8:171-178.

32 Kundel HL, Polansky M. Measurement of observer agreement. Radiology 2003;228:303-308.

33 Zhang Y, Wang L, Li Y et al. Protein expression of programmed death 1 ligand 1 and ligand 2 independently predict poor prognosis in surgically resected lung adenocarcinoma. Onco Targets Ther 2014;7: 567-573.

34 Marzec M, Zhang Q, Goradia A et al. Oncogenic kinase NPM/ALK induces through STAT3 expression of immunosuppressive protein CD274 (PD-L1, B7-H1). Proc Natl Acad Sci USA 2008;105:20852-20857.

35 Wilke CM, Wei S, Wang L et al. Dual biological effects of the cytokines interleukin-10 and interferon-gamma. Cancer Immunol Immunother 2011;60:1529-1541.

36 Parsa AT, Waldron JS, Panner A et al. Loss of tumor suppressor PTEN function increases B7-H1 expression and immunoresistance in glioma. Nat Med 2007;13: 84-88.

37 Jiang X, Zhou J, Giobbie-Hurder A et al. The activation of MAPK in melanoma cells resistant to BRAF inhibition promotes PD-L1 expression that is reversible by MEK and PI3K inhibition. Clin Cancer Res 2013;19:598-609.

38 Gelsomino F, Facchinetti F, Haspinger ER et al. Targeting the MET gene for the treatment of nonsmall-cell lung cancer. Crit Rev Oncol Hematol 2014; 89:284-299.

39 Engelman JA, Zejnullahu K, Mitsudomi T et al. MET amplification leads to gefitinib resistance in lung cancer by activating ERBB3 signaling. Science 2007; 316:1039-1043.

40 Konishi J, Yamazaki K, Azuma M et al. B7-H1 expression on non-small cell lung cancer cells and its relationship with tumor-infiltrating lymphocytes and their PD-1 expression. Clin Cancer Res 2004;10:5094-5100.

$41 \mathrm{Mu}$ CY, Huang JA, Chen Y et al. High expression of PDL1 in lung cancer may contribute to poor prognosis and tumor cells immune escape through suppressing tumor infiltrating dendritic cells maturation. Med Oncol 2011;28:682-688. 
42 Chen YB, Mu CY, Huang JA. Clinical significance of programmed death-1 ligand-1 expression in patients with non-small cell lung cancer: a 5-year-followup study. Tumori 2012;98:751-755.

43 Soria JC, Cruz C, Bahleda R et al. Clinical activity, safety and biomarkers of PD-L1 blockade in non-small cell lung cancer (NSCLC): additional analyses from a clinical study of the engineered antibody MPDL3280A (antiPDL1). Eur J Cancer 2013;49: Abstract 3408.

44 Azuma T, Yao S, Zhu G et al. B7-H1 is a ubiquitous antiapoptotic receptor on cancer cells. Blood 2008;111: 3635-3643.

45 Liu H, Zhang T, Ye J et al. Tumor-infiltrating lymphocytes predict response to chemotherapy in patients with advance non-small cell lung cancer. Cancer Immunol Immunother 2012;61:1849-1856.
46 Hamanishi J, Mandai M, Iwasaki M et al. Programmed cell death 1 ligand 1 and tumor-infiltrating CD8+ T lymphocytes are prognostic factors of human ovarian cancer. Proc Natl Acad Sci USA 2007;104:3360-3365.

47 Al-Shibli KI, Donnem T, Al-Saad S et al. Prognostic effect of epithelial and stromal lymphocyte infiltration in non-small cell lung cancer. Clin Cancer Res 2008;14: 5220-5227.

48 Badoual C, Hans S, Merillon N et al. PD-1-expressing tumor-infiltrating $\mathrm{T}$ cells are a favorable prognostic biomarker in HPV-associated head and neck cancer. Cancer Res 2013;73:128-138.

$49 \mathrm{Hsu} \mathrm{MC}$, Hsiao JR, Chang $\mathrm{KC}$ et al. Increase of programmed death-1-expressing intratumoral CD8 $\mathrm{T}$ cells predicts a poor prognosis for nasopharyngeal carcinoma. Mod Pathol 2010;23:1393-1403.

Supplementary Information accompanies the paper on Modern Pathology website (http://www.nature.com/ modpathol) 